\title{
DIMENSI PARTISI DARI GRAF PERSAHABATAN
}

\author{
GILANG ARYA LIZA \\ Jurusan Matematika, \\ Fakultas Matematika dan Ilmu Pengetahuan Alam, Universitas Andalas, \\ Kampus UNAND Limau Manis Padang, Indonesia. \\ email : gilank.praksos@gmail.com
}

\begin{abstract}
Abstrak. Dimensi partisi diperkenalkan pertama kali oleh Chartrand, Salehi dan Zhang [2] pada tahun 1998. Dimensi partisi merupakan pengelompokan semua titik di $G$ ke dalam sejumlah kelas partisi dan menentukan jarak setiap titik terhadap setiap kelas partisi tersebut [2] dan dinotasikan sebagai $p d(G)$ untuk graf terhubung. Pemilihan representasi yang tepat menghasilkan suatu representasi dimana semua titiknya memiliki vektor koordinat yang berbeda. Pada tulisan ini, akan dibahas kembali makalah [4] tentang cara penentuan dimensi partisi dari graf persahabatan. Graf persahabatan adalah graf lengkap $K_{2}$ yang digandakan sebanyak $n$ kali dan dihubungkan dengan sebuah titik dari $K_{1}$. Akibatnya semua titik di $K_{2}$ akan terhubung dengan titik di $K_{1}$. Titik di $K_{1}$ pada graf persahabatan disebut dengan titik pusat $c$. Graf persahabatan dapat dinotasikan dengan $f_{n}$.
\end{abstract}

Kata Kunci: Dimensi partisi, representasi, graf persahabatan

\section{Pendahuluan}

Graf adalah pasangan himpunan titik dan himpunan sisi. Pada dasarnya, graf digunakan untuk menggambarkan berbagai macam struktur yang ada dengan tujuan supaya penggambaran objek-objek tersebut lebih mudah dipahami dan dimengerti. Beberapa contoh yang digunakan dalam kehidupan sehari-hari adalah jaringan pertemanan instagram, peta rangkaian listrik, bagan air dan lain-lain.

Kemudian, yang perlu diperhatikan yaitu istilah partisi. Partisi merupakan pembagian beberapa kelompok atau kelas suatu graf. Representasi dikenalkan secara terpisah oleh Slater (1975) dan dikenalkan juga oleh Harary dan Melter (1975) kemudian digunakan oleh seorang kimiawan pada sebuah perusahaan farmasi Johnson (1993). Konsepnya yaitu senyawa kimia tersebut direpresentasikan secara unik sebagai objek dari matematika. Selanjutnya dalam [1] juga dikatakan bahwa klasifikasi senyawa kimia dilakukan dengan mempelajari dan mengklasifikasi objek matematika tersebut. Senyawa kimia tersebut direpresentasikan dalam bentuk graf dengan simpul graf menyatakan atom dan sisi graf menyatakan ikatan valensi antara dua atom.

Selanjutnya, Chartrand dkk. [2] pada paper pertama tentang dimensi partisi menunjukkan dimensi partisi graf bintang ganda $T$ dan memberikan batas atas dan batas bawah tentang dimensi partisi graf ulat (caterpillar). Selanjutnya pada makalah yang sama juga diperoleh bahwa graf $\mathrm{G}$ mempunyai $p d(G)=n$ jika dan hanya jika $G \cong K_{n}$, serta graf $G$ mempunyai $p d(G)=2$ jika dan hanya jika $G$ 
adalah graf lintasan $P_{n}$.

Pengenalan konsep partisi pembeda telah dinyatakan oleh Chartrand dkk. [2] yang merupakan bentuk serupa dari himpunan pembeda dari suatu graf. Chartrand dkk. [2] menyatakan bahwa dalam merepresentasikan setiap titik pada suatu graf $G$, yang harus dilakukan yaitu mengelompokkan titik di graf $G$ ke dalam sejumlah kelas partisi kemudian hitung jarak tersebut ke setiap titik di $G$.

Oleh karena itu, dalam makalah ini akan dikaji kembali makalah [4] tentang penentuan dimensi partisi dari graf persahabatan $f_{n}$ untuk $n \geq 1$. Graf persahabatan adalah graf lengkap $K_{2}$ yang digandakan sebanyak n kali dengan menghubungkan semua titik dari graf $n K_{2}$ dengan suatu titik di $K_{1}$. Untuk selanjutnya, titik $K_{1}$ disebut titik pusat $c$.

\section{Dimensi Partisi Dari Graf Persahabatan}

Pada bab ini akan dibahas mengenai dimensi partisi dari graf persahabatan $f_{n}$, seperti yang telah dibahas pada disertasi Darmaji [4]. Graf persahabatan $f_{n}$ adalah graf yang mempunyai $n$ buah pasang titik yang masing-masing disimbolkan dengan $a_{i}$ dan $b_{i}$ dengan $1 \leq i \leq n$. Pada Gambar 1 adalah bentuk dari graf persahabatan $f_{n}$.

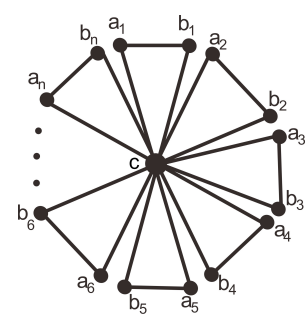

Gambar 1. Graf Persahabatan $f_{n}$

Di bawah ini akan dipaparkan mengenai lema dan teorema yang mendukung dalam penulisan makalah ini.

Lema 2.1. [4] Misalkan terdapat suatu partisi pembeda $\Pi$ untuk graf persahabatan $f_{n}$ dengan $n \geq 1$ dengan himpunan titik $V\left(f_{n}\right)=\left\{c, a_{i}, b_{i} \mid i=1,2, \cdots, n\right\}$ dan terdapat himpunan sisi $E\left(f_{n}\right)=\left\{c a_{i}, a_{i} b_{i}, c_{i} b_{i} \mid i=1,2, \cdots, n\right\}$. Maka titik $a_{i}$ dan $b_{i}$ harus termuat dalam kelas partisi berbeda di $\Pi$.

Lema 2.2. [4] Misalkan terdapat suatu partisi pembeda $\Pi$ untuk graf persahabatan $f_{n}, n \geq 1$ dimana terdapat himpunan titik $V\left(f_{n}\right)=\left\{c, a_{i}, b_{i} \mid i=1,2, \cdots, n\right\}$ dan himpunan sisi $E\left(f_{n}\right)=\left\{c a_{i}, a_{i} b_{i}, c_{i} b_{i} \mid i=1,2, \cdots, n\right\}$. Misalkan $S_{x}$ adalah sebuah kelas partisi di $\Pi$ yang memuat $x$. Jika untuk setiap $i$, didefinisikan $L_{i}=\{u, v\}$, sedemikian hingga titik $a_{i} \in S_{u}$ dan titik $b_{i} \in S_{v}$, maka $L_{i} \neq L_{j}$ untuk $i \neq j$.

Teorema 2.3. [1] Dimensi partisi sebuah graf persahabatan $f_{n}$ adalah $k$, dengan $k$ merupakan bilangan bulat terkecil sedemikian hingga $\left(\begin{array}{l}k \\ 2\end{array}\right) \geq n$. 
Bukti. Untuk setiap $i=1,2, \cdots, n$, misalkan $\left\{a_{i}, b_{i}\right\}$ adalah dua titik bertetangga di graf $f_{n}$. Misalkan terdapat suatu partisi pembeda $\Pi$ untuk graf persahabatan $f_{n}$. Berdasarkan Lema 2.1 dan Lema 2.2, titik $a_{i}$ dan $b_{i}$ harus termuat dalam kelas partisi berbeda di $\Pi$, dan $L_{i} \neq L_{j}$ untuk $i \neq j$. Definisi untuk $L_{i}$ mengikuti yang terdapat di Lema 2.1 dan 2.2. Oleh karena itu, jumlah kelas partisi di $\Pi$ sedikitnya $k$ buah kelas partisi, dengan $k$ merupakan bilangan bulat terkecil yang memenuhi $\left(\begin{array}{l}k \\ 2\end{array}\right) \geq n$. Dengan demikian, $p d\left(f_{n}\right) \geq k$. Sekarang akan ditunjukkan bahwa $p d\left(f_{n}\right) \leq$ $k$. Pandang suatu partisi pembeda $\Pi=\left\{S_{1}, S_{2}, \cdots, S_{k}\right\}$ yang diperoleh dengan menandai $\left.L_{i}, i=1,2, \cdots, n\right)$ dengan kombinasi-2 dari $\{1,2, \cdots, k\}$ sedemikian hingga $L_{i} \neq L j$ dimana titik $i \neq j$, dan andaikan $c \in S_{1}$. Karena representasi $r(v \mid \Pi)$ adalah unik untuk setiap $v \in V\left(f_{n}\right)$, maka $\Pi$ adalah suatu partisi pembeda dari graf $f_{n}$. Dengan demikian, $p d\left(f_{n}\right) \leq k$, dengan $k$ bilangan bulat terkecil sedemikian hingga $\left(\begin{array}{l}k \\ 2\end{array}\right) \geq n$.

(Kasus 1) Misalkan terdapat graf persahabatan $f_{n}$ dengan $n \geq 1$, akan ditentukan dimensi partisi graf persahabatan $f_{1}$. Misalkan $i=1$. Dalam hal ini, terdapat titik-titik $V\left(f_{1}\right)=\left\{c, a_{1}, b_{1}\right\}$ dan terdapat sisi $E\left(f_{1}\right)=\left\{c a_{1}, c b_{1}, a_{1} b_{1}\right\}$.

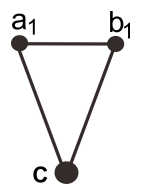

Gambar 2. Graf Persahabatan $f_{1}$

(Kasus 2) Misalkan terdapat graf persahabatan $f_{n}$ dengan $n \geq 1$, akan ditentukan dimensi partisi dari graf persahabatan $f_{2}$. Misalkan $i=1,2$. Dalam hal ini, terdapat titik-titik $V\left(f_{2}\right)=\left\{c, a_{1}, b_{1}, a_{2}, b_{2}\right\}$ dan terdapat sisi $E\left(f_{2}\right)=$ $\left\{c a_{1}, c b_{1}, a_{1} b_{1}, c a_{2}, c b_{2}, a_{2} b_{2}\right\}$.

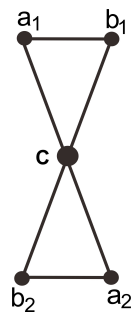

Gambar 3. Graf Persahabatan $f_{2}$

SubKasus 2.1 Misalkan $p d\left(f_{2}\right)=2$.

Himpunan partisi graf $f_{2}$ dapat didefinisikan sebagai $\Pi_{1}=\left\{S_{1}, S_{2}\right\}$, dengan

$$
\begin{aligned}
& S_{1}=\left\{a_{1}, b_{2}, c\right\}, \\
& S_{2}=\left\{b_{1}, a_{2}\right\} .
\end{aligned}
$$


Diperoleh representasi di semua titik dari $f_{2}$ adalah sebagai berikut:

$$
\begin{aligned}
r\left(a_{1} \mid \Pi_{1}\right) & =(0,1), \\
r\left(b_{2} \mid \Pi_{1}\right) & =(0,1), \\
r\left(c \mid \Pi_{1}\right) & =(0,1), \\
r\left(b_{1} \mid \Pi_{1}\right) & =(1,0), \\
r\left(a_{2} \mid \Pi_{1}\right) & =(1,0) .
\end{aligned}
$$

Berdasarkan representasi diatas, akan terlihat bahwa nilai representasi dari $a_{1}, b_{2}$ dan $c$ bernilai sama yaitu $(0,1)$ serta $b_{1}$ dan $a_{2}$ juga bernilai sama yaitu $(1,0)$.

SubKasus 2.2 Misalkan $p d\left(f_{2}\right)=3$.

Himpunan partisi graf $f_{2}$ dapat didefinisikan sebagai $\Pi_{2}=\left\{S_{1}, S_{2}, S_{3}\right\}$, dengan

$$
\begin{aligned}
& S_{1}=\left\{a_{1}, c\right\}, \\
& S_{2}=\left\{b_{1}, a_{2}\right\}, \\
& S_{3}=\left\{b_{2}\right\} .
\end{aligned}
$$

Diperoleh representasi di semua titik dari $f_{2}$ adalah sebagai berikut:

$$
\begin{aligned}
r\left(a_{1} \mid \Pi_{2}\right) & =(0,1,2), \\
r\left(c \mid \Pi_{2}\right) & =(0,1,1), \\
r\left(b_{1} \mid \Pi_{2}\right) & =(1,0,2), \\
r\left(a_{2} \mid \Pi_{2}\right) & =(1,0,1), \\
r\left(b_{2} \mid \Pi_{2}\right) & =(1,1,0) .
\end{aligned}
$$

Berdasarkan representasi diatas, akan terlihat bahwa nilai representasi dari $a_{1}, c, b_{1}, a_{2}, b_{2}$ semuanya bernilai berbeda.

Berdasarkan hasil dari uraian diatas, akan terlihat bahwa dimensi partisi graf persahabatan $f_{1}$ yaitu $p d\left(f_{1}\right)=3$, karena $\left(\begin{array}{l}3 \\ 2\end{array}\right)=3 \geq 2$. Sehingga jumlah kelas partisi $\Pi$ sedikitnya adalah 3 .

(Kasus 3) Misalkan dimensi partisi graf persahabatan $f_{n}$ dengan $n \geq 1$, akan ditunjukkan bilangan bulat terkecil dari graf persahabatan $f_{3}$. Misalkan $i=$ 1,2,3. Dalam hal ini, terdapat titik-titik $V\left(f_{3}\right)=\left\{c, a_{1}, b_{1}, a_{2}, b_{2}, a_{3}, b_{3}\right\}$ dan terdapat sisi $E\left(f_{3}\right)=\left\{c a_{1}, c b_{1}, a_{1} b_{1}, c a_{2}, c b_{2}, a_{2} b_{2}, c a_{3}, c b_{3}, a_{3} b_{3}\right\}$.

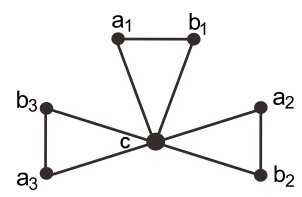

Gambar 4. Graf Persahabatan $f_{3}$ 
(Kasus 4) Misalkan dimensi partisi graf persahabatan $f_{n}$ dengan $n \geq 1$, bilangan bulat terkecil dari graf persahabatan $f_{4}$. Misalkan $i=1,2,3,4$. Dalam hal ini, terdapat titik $V\left(f_{4}\right)=\left\{c, a_{1}, b_{1}, a_{2}, b_{2}, a_{3}, b_{3}, a_{4}, b_{4}\right\}$ dan sisi-sisi $E\left(f_{4}\right)=\left\{c a_{1}, c b_{1}, a_{1} b_{1}, c a_{2}, c b_{2}, a_{2} b_{2}, c a_{3}, c b_{3}, a_{3} b_{3}, c a_{4}, c b_{4}, a_{4} b_{4}\right\}$.

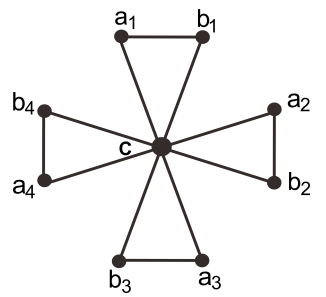

Gambar 5. Graf Persahabatan $f_{4}$

(Kasus 5) Misalkan graf persahabatan $f_{n}$ dengan $n \geq 1$, akan ditunjukkan bilangan bulat terkecil dari graf persahabatan $f_{5}$. Misalkan $i=1,2,3,4,5$. Dalam hal ini, titik $V\left(f_{5}\right)=\left\{c, a_{1}, b_{1}, a_{2}, b_{2}, a_{3}, b_{3}, a_{4}, b_{4}, a_{5}, b_{5}\right\}$ sisi $E\left(f_{5}\right)=$ $\left\{c a_{1}, c b_{1}, a_{1} b_{1}, c a_{2}, c b_{2}, a_{2} b_{2}, c a_{3}, c b_{3}, a_{3} b_{3}, c a_{4}, c b_{4}, a_{4} b_{4}, c a_{5}, c b_{5}, a_{5} b_{5}\right\}$.

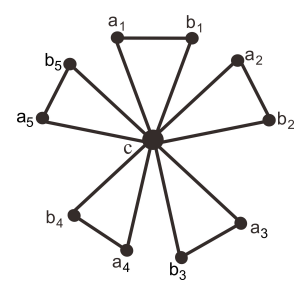

Gambar 6. Graf Persahabatan $f_{5}$

(Kasus 6) Misalkan dimensi partisi graf persahabatan $f_{n}$ dengan $n \geq 1$, akan ditunjukkan bilangan bulat terkecil dari graf persahabatan $f_{6}$. Misalkan $i=$ $1,2,3,4,5,6 . V\left(f_{5}\right)=\left\{c, a_{1}, b_{1}, a_{2}, b_{2}, a_{3}, b_{3}, a_{4}, b_{4}, a_{5}, b_{5}, a_{6}, b_{6}\right\}, E\left(f_{5}\right)=$ $\left\{c a_{1}, c b_{1}, a_{1} b_{1}, c a_{2}, c b_{2}, a_{2} b_{2}, c a_{3}, c b_{3}, a_{3} b_{3}, c a_{4}, c b_{4}, a_{4} b_{4}, c b_{5}, a_{5} b_{5}, c b_{6}, a_{6} b_{6}\right\}$.

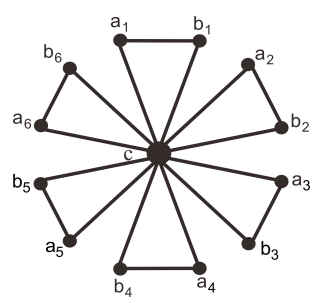

Gambar 7. Graf Persahabatan $f_{6}$ 
(Kasus 7) Misalkan dimensi partisi graf persahabatan $f_{n}$ dengan $n \geq 1$, akan ditunjukkan bilangan bulat terkecil dari graf persahabatan $f_{7}$. Misalkan $i=\{1,2,3,4,5,6,7\}$. Dalam hal ini, terdapat titik-titik $V\left(f_{7}\right)=$ $\left\{c, a_{1}, b_{1}, a_{2}, b_{2}, a_{3}, b_{3}, a_{4}, b_{4}, a_{5}, b_{5}, a_{6}, b_{6}, a_{7}, b_{7}\right\}$ dan Sisi-sisi $E\left(f_{7}\right)=$ $\left\{c a_{1}, c b_{1}, a_{1} b_{1}, c a_{2}, c b_{2}, a_{2} b_{2}, c a_{3}, c b_{3}, a_{3} b_{3}, c a_{4}, c b_{4}, a_{4} b_{4}, c b_{5}, a_{5} b_{5}, c b_{6}, a_{6} b_{6}\right.$, $\left.c b_{7}, a_{7}, b_{7}\right\}$.

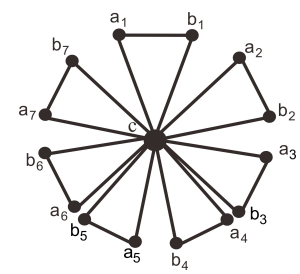

Gambar 8. Graf Persahabatan $f_{7}$

Dari Kasus 1 sampai dengan Kasus 3 jumlah kelas partisi $\Pi$ sedikitnya adalah 3. Untuk Kasus 4 sampai dengan Kasus 6 jumlah kelas partisi $\Pi$ sedikitnya adalah 4 . Sedangkan pada Kasus 7 diperoleh bahwa jumlah kelas partisi $\Pi$ sedikitnya adalah 5.

\section{Kesimpulan}

Dimensi partisi dari graf persahabatan $f_{n}$ adalah $k$, dengan $k$ merupakan bilangan bulat terkecil sedemikian hingga $\left(\begin{array}{l}k \\ 2\end{array}\right) \geq n$ dan dapat disimpulkan juga bahwa dalam menentukan dimensi partisi tersebut tidak boleh mengambil titik-titik di kelas partisi yang sama dikarenakan nilai representasinya akan sama sehingga haruslah memilih titik-titik di kelas partisi yang berbeda.

\section{Ucapan Terima kasih}

Pada penulisan artikel ini, penulis mengucapkan terima kasih kepada bapak Narwen, ibu Lyra Yulianti, ibu Izzati Rahmi HG, bapak Effendi dan ibu Susila Bahri yang telah memberikan kritik dan saran kepada penulis dalam penulisan artikel ini.

\section{Daftar Pustaka}

[1] Bondy, J. A. and U. S. R Murty. 1976. Graph Theory with Applications. Elsevier Science Published Co., Inc, New York.

[2] Chartrand,G.,Salehi, E., dan Zhang, P., (1998): On the partition dimension of graph .Congr. Numerantium. $130: 157-168$.

[3] Chartrand,G.,Salehi, E., dan Zhang, p.,(2000): The partition dimension of graph, Aequationes Math. 59: 45 - 54.

[4] Darmaji.2011. Dimensi Partisi Graf Multipartit dan Graf Hasil Korona Dua Graf Terhubung, Disertasi Doktor, tidak diterbitkan, Sekolah Pascasarjana Institut Teknologi Bandung, ITB. 